\title{
Angiotensin II induces monocyte chemoattractant protein-1 expression by increasing reactive oxygen species-mediated activation of the nuclear factor- $\kappa B$ signaling pathway in osteoblasts
}

\author{
CHANGYAO WANG $^{1}$, CAILONG ZHANG $^{1}$, FENG ZHOU $^{1}$, LEI GAO ${ }^{1}$, \\ YINGZHEN WANG $^{1}$, CHUNSHENG WANG $^{2}$ and YONGTAO ZHANG ${ }^{1}$ \\ ${ }^{1}$ Department of Orthopedics, The Affiliated Hospital of Qingdao University, Qingdao, Shandong 266061; \\ ${ }^{2}$ Department of Orthopaedics, The Second Affiliated Hospital of Xi'an Jiaotong University, Xi'an, Shaanxi 710004, P.R. China
}

Received April 17, 2016; Accepted September 9, 2017

DOI: $10.3892 / \mathrm{mmr} .2017 .7971$

\begin{abstract}
The present study investigated the effect of angiotensin II (Ang II) on monocyte chemoattractant protein-1 (MCP-1) expression and the underlying mechanism in osteoblasts. MCP-1 expression levels were analyzed by ELISA and reverse transcription-quantitative polymerase chain reaction (RT-qPCR). Ang II type 1 receptor (AT1R) expression levels was examined by RT-qPCR, western blotting and immunostaining. In addition, the nuclear factor (NF)- $\kappa \mathrm{B}$ signaling pathway was investigated via western blot analysis. Reactive oxygen species (ROS) were also detected by flow cytometry and fluorescent microscopy. The results of the present study ndicated that Ang II upregulated MCP-1 expression in osteoblasts, which was mitigated by agonists of the AT1R, including olmesartan, a ROS scavenger N-acetylcysteine (NAC), ammonium pyrrolidinethiocarbamate (PDTC) and nuclear factor (NF) $-\kappa \mathrm{B}$, but not by the Ang II type 2 receptor antagonist, PD123319. Furthermore, Ang II increased the generation of ROS and activated the NF- $\kappa \mathrm{B}$ signaling pathway. These effects of Ang II were blocked by olmesartan, NAC and PDTC, but not by PD1123319 in osteoblasts. In conclusion, these data indicated that Ang II enhanced ROS production and activated
\end{abstract}

Correspondence to: Dr Yongtao Zhang, Department of Orthopedics, The Affiliated Hospital of Qingdao University, 59 Hai Er Road, Qingdao, Shandong 266061, P.R. China

E-mail: drzhang215@163.com

Abbreviations: Ang II, angiotensin II; AT1R, angiotensin II type 1 receptor; AT2R, angiotensin II type 2 receptor; MCP-1, monocyte chemoattractant protein-1; RANKL, receptor activator of nuclear factor- $\kappa \mathrm{B}$ ligand; RAS, renin-angiotensin system; ROS, reactive oxygen species

Key words: angiotensin II, osteoblasts, monocyte chemoattractant protein-1, reactive oxygen species, nuclear factor- $\kappa \mathrm{B}$ pathway
NF- $\mathrm{B}$ signaling via AT1R, thus upregulating MCP-1 expression in osteoblasts.

\section{Introduction}

Angiotensin II (Ang II), a primary effector in the renin-angiotensin system (RAS), regulates cell growth and differentiation, blood pressure, fluid and electrolyte homeostasis, and cytokine production (1). Ang II is crucial for renal and cardiovascular function (2), and previous studies have demonstrated that Ang II induces receptor activator of nuclear factor- $\kappa \mathrm{B}$ ligand (RANKL) expression in osteoblasts, leading to osteoclast activation and accelerated osteoporosis (3-5). During bone metabolism, monocyte chemoattractant protein-1 (MCP-1) secreted by osteoblast is important for osteoclast nactivation (6). However, whether Ang II upregulates MCP-1 expression in osteoblasts remains to be investigated.

Ang II stimulates MCP-1 expression in endothelia cells, vascular smooth muscle cells (VSMCs) and monocytes. Ang II upregulates MCP-1 expression in rat glomerular endothelial cells by activating the NAD(P)H oxidase-dependent nuclear factor (NF)- $\kappa \mathrm{B}$ signaling pathway (7). Furthermore, Ang II enhances MCP-1 expression in proximal tubular cells by activating reactive oxygen species (ROS)-mediated signaling (8). In addition, Ang II through its Ang II receptor type 1 (AT1R) promotes ROS generation in hepatocytes (9). Previous studies have indicated that ROS activates NF- $\kappa$ B signaling (10). However, whether Ang II also induces ROS production which activates the NF- $\mathrm{NB}$ signaling pathway, resulting in upregulated MCP-1 expression in osteoblasts, remains to be clarified.

The present study used the MC3T3-E1 mouse osteoblastic cell line to investigate the hypothesis that Ang II induces ROS production to activate the NF- $\kappa \mathrm{B}$ signaling pathway, and upregulates MCP-1 expression in osteoblasts.

\section{Materials and methods}

Materials. $\alpha$-Modified minimum essential medium ( $\alpha$-MEM), fetal bovine serum (FBS), streptomycin and penicillin 
Table I. Primers sequences for reverse transcription-quantitative polymerase chain reaction.

\begin{tabular}{llr}
\hline Target & \multicolumn{1}{c}{ Primer sequence (5'-3') } & GenBank no. \\
\hline MCP-1 & F: TCACCTGCTGCTACTCATTC & NM_011333.3 \\
& R: ATGTCTGGACCCATTCCTTC & NM_009642.4 \\
AT1R & F: CTCTTGCTGCCTCGTCTACC & NM_007393.3 \\
& R: TGCAGCAGCGTCTGATGATG & F: AGGCCAACCGTGAAAAGATG \\
& R: TGGCGTGAGGGAGAGCATAG & \\
\hline
\end{tabular}

AT1R, Angiotensin II type 1 receptor; MCP-1, Monocyte chemoattractant protein-1; F, forward; R, reverse.

were purchased from Gibco; Thermo Fisher Scientific, Inc. (Waltham, MA, USA). Ang II, PD123319, N-acetylcysteine (NAC), 2',7'-dichlorodihydrofluorescein diacetate (DCFH-DA) and ammonium pyrrolidine thiocarbamate (PDTC) were obtained from Sigma-Aldrich; Merck KGaA (Darmstadt, Germany). A rabbit anti-mouse AT1R (ab18801), anti-mouse I $\mathrm{B}$ kinase $(\mathrm{IKK}) \beta(\mathrm{ab32135})$ and anti-mouse phosphorylated (p)-IKK $\beta$ antibodies (ab59195) were purchased from Abcam (Cambridge, MA, USA). In addition, rabbit polyclonal

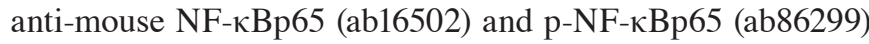
antibodies were obtained from Abcam. Rabbit polyclonal anti-mouse I $\mathrm{B} \alpha$ (sc371), and mouse monoclonal anti-mouse $\beta$-actin antibody (sc47778), were obtained from Santa Cruz Biotechnology, Inc. (Dallas, TX, USA).

Cell culture. All MC3T3-E1 cells (American Type Culture Collection, Manassas, VA, USA) were grown to $\sim 80 \%$ confluence and were routinely grown overnight in $10 \% \mathrm{FBS}$ supplemented with $\alpha$-MEM containing $100 \mathrm{U} / \mathrm{ml}$ penicillin and $100 \mu \mathrm{g} / \mathrm{ml}$ streptomycin at $37^{\circ} \mathrm{C}$ in $5 \% \mathrm{CO}_{2}$ and $95 \%$ air. In order to determine the effects of Ang II on MCP-1 expression in the MC3T3-E1 cells, the cells were treated with $10^{-9 \sim-5} \mathrm{M}$ Ang II or without Ang II (control group) for $24 \mathrm{~h}$ at $37^{\circ} \mathrm{C}$ and were treated with $10^{-6} \mathrm{M}$ Ang II for varying durations $(0,3,6,12,18$ and $24 \mathrm{~h})$ at $37^{\circ} \mathrm{C}$. Furthermore, cells were in the presence of $10^{-6} \mathrm{M}$ Ang II or absence of Ang II which served as the control group; cells were then separated into groups that were pretreated with $10^{-5} \mathrm{M}$ olmesartan (AT1R blocker), $10^{-5}$ M PD123319 (AT2R blocker), $10^{-3} \mathrm{M}$ N-acetylcysteine (NAC, a scavenger of free radicals), or $5 \times 10^{-6} \mathrm{M}$ PDTC (the $\mathrm{NF}-\kappa \mathrm{B}$ inhibitor) for $24 \mathrm{~h}$ at $37^{\circ} \mathrm{C}$. The cells were harvested for subsequent analysis.

Reverse transcription-quantitative polymerase chain reaction $(R T-q P C R)$. Total RNA was extracted from different groups of MC3T3-E1 cells by TRIzol reagent (Invitrogen; Thermo Fisher Scientific, Inc.) and the cDNA was generated using the Revert Aid $^{\mathrm{TM}}$ First Strand cDNA Synthesis kit (Fermentas; Thermo Fisher Scientific, Inc.) according to manufacturer's protocol. The relative levels of MCP-1 and AT1R gene mRNA transcripts to control $\beta$-actin in different groups of cells were determined using the cDNA as the template, the SYBR Green 1 PCR master mix (Takara Bio, Inc., Otsu, Japan), under the following conditions: $95^{\circ} \mathrm{C}$ for $30 \mathrm{sec}, 95^{\circ} \mathrm{C}$ for $5 \mathrm{sec}$, and $60^{\circ} \mathrm{C}$ for $30 \mathrm{sec}$ for 40 cycles and $95^{\circ} \mathrm{C}$ for $15 \mathrm{sec}$ in an ABI 7300 Real-time
PCR system (Bio-Rad Laboratories, Inc., Hercules, CA, USA). The primer sequence are presented in Table I. The data were normalized to the control $\beta$-actin expression and analyzed by $2^{-\Delta \Delta \mathrm{Cq}}$ method (11). All assays were performed in quintuplicate.

ELISA. The levels of MCP-1 in the supernatants of cultured MC3T3-E1 cells were determined by ELISA using a specific kit (ab100721), according to the manufacturer's protocol (Abcam). The limitation of MCP-1 detection was $10 \mathrm{pg} / \mathrm{ml}$.

Western blot analysis. The different groups of MC3T3-E1 cells were washed with ice-cold PBS, and lysed in radioimmunoprecipitation assay buffer (Thermo Fisher Scientific, Inc.). The cell lysates were centrifuged at $10,000 \mathrm{x}$ g for $20 \mathrm{~min}$ at $4^{\circ} \mathrm{C}$. The concentration of protein was quantified by the Bicinchoninic Acid protein assay reagent (Pierce; Thermo Fisher Scientific, Inc.). The lysates $(20 \mu \mathrm{g} / \mathrm{lane})$ were subjected to $5 \%$ and $10 \%$ SDS-PAGE, which was performed using a constant voltage of $90 \mathrm{~V}$ for $120 \mathrm{~min}$. Following this, proteins were transferred onto polyvinyl difluoride membranes. The membranes were blocked with $5 \%$ fat-free milk and probed with anti-AT1R

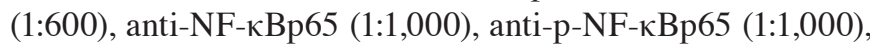
anti-I $\mathrm{B} \alpha(1: 1,000)$, anti-IKK $\beta(1: 1,000)$, anti-p-IKK $\beta$ (1:500) and anti- $\beta$-actin (1:100) primary antibodies respectively, and incubated overnight at $4^{\circ} \mathrm{C}$. Following three washes with PBS, the bound antibodies were detected with horseradish peroxidase-conjugated mouse anti-rabbit immunoglobulin $\mathrm{G}$ ( IgG; 1:3,000, sc2357) secondary antibody, which was obtained from Santa Cruz Biotechnology, Inc., at room temperature for $2 \mathrm{~h}$. The bands were visualized by an Enhanced ECL Chemiluminescent Substrate kit (JC-PC001, Jingcai Biotechnology Co. Ltd., Xi'an, China). The relative levels of each target protein to the control $\beta$-actin were analyzed using Quantity One v4.52 software (Bio-Rad Laboratories, Inc.).

Immunostaining. The cells were pre-treated with $10^{-5} \mathrm{M}$ olmesartan (an AT1R blocker) for $30 \mathrm{~min}$, and exposed to Ang II $\left(10^{-6} \mathrm{M}\right)$ for $12 \mathrm{~h}$. The cells were fixed with $10 \%$ methanol at room temperature, blocked with rabbit serum in PBS for $60 \mathrm{~min}$ at room temperature, and subsequently stained with an anti-AT1R antibody (1:500) overnight at $4^{\circ} \mathrm{C}$. Following three washes with PBS, the cells were incubated with goat anti-rabbit $\mathrm{IgG}$ secondary antibody for $2 \mathrm{~h}$ at $37^{\circ} \mathrm{C}(1: 200$, cw0159), which was obtained from ComWin Biotech Co., Ltd. (Beijing, China). The cells were washed with PBS for three 

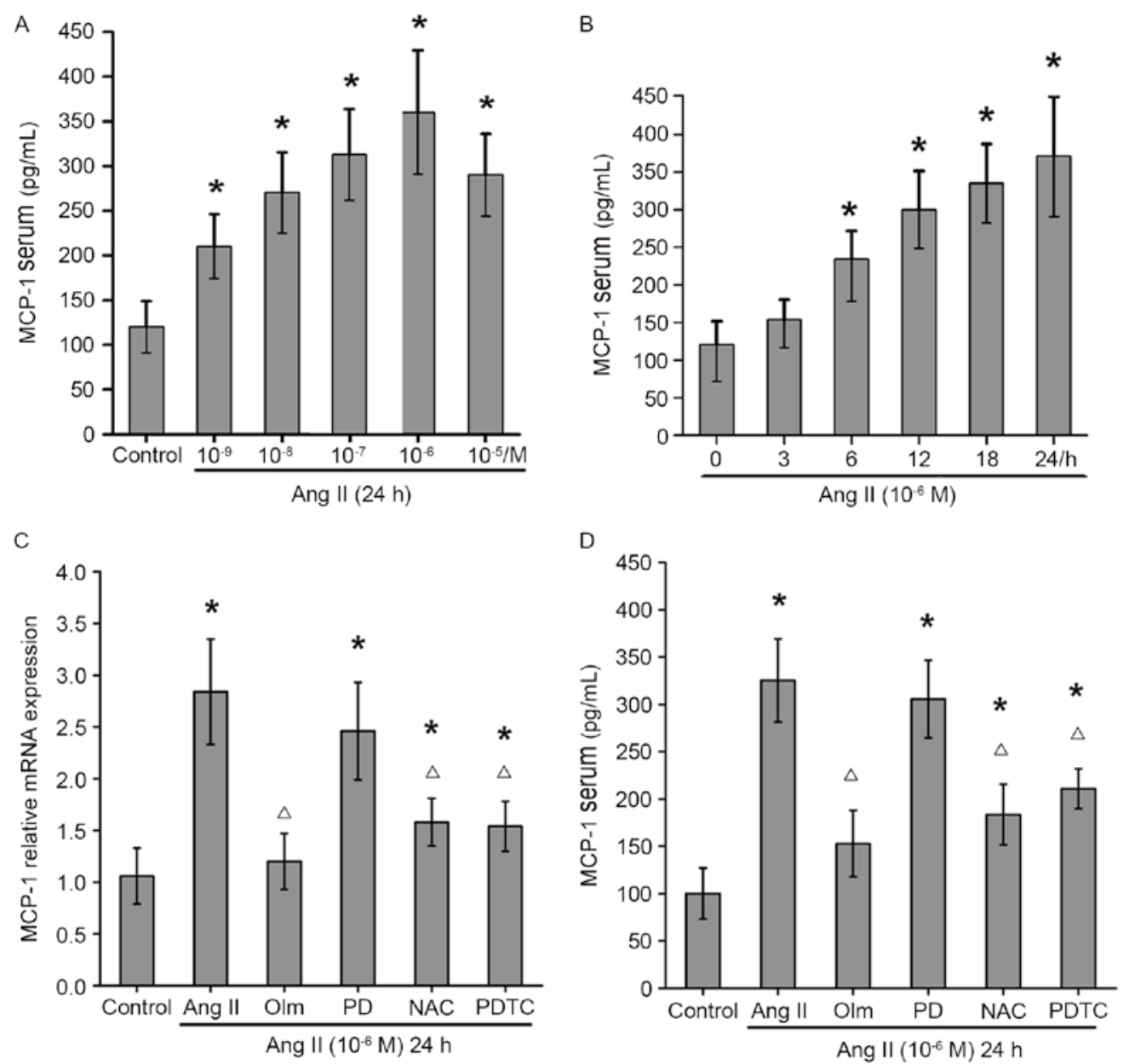

Figure 1. Effects of Ang II on MCP-1 expression in osteoblasts. MCP-1 expression levels following (A) various doses of Ang II, and (B) treatment with $10^{-6} \mathrm{M}$ Ang II for 0, 3, 6, 12, 18 and $24 \mathrm{~h}$. (C) mRNA expression and (D) serum levels of MCP-1 following treatment with Ang II and various inhibitors, as assessed by reverse transcription-quantitative polymerase chain reaction and ELISA, respectively. Data are expressed as the mean \pm standard deviation of five independent experiments. ${ }^{*} \mathrm{P}<0.05$ vs. control; ${ }^{\triangle} \mathrm{P}<0.05$ vs. Ang II. Ang II, angiotensin II; MCP-1, monocyte chemoattractant protein-1; Olm, olmesartan; PD, PD123319; NAC, N-acetylcysteine; PDTC, ammonium pyrrolidine thiocarbamate.

times prior to staining with with phycoerythrin-streptavidin and DAPI (Sigma-Aldrich; KGaA). Images were obtained under a fluorescent microscope at excitation wavelengths of 550 and $340 \mathrm{~nm}$ (BX50; Olympus Corporation, Tokyo, Japan).

Flow cytometry and fluorescent microscopy. Intracellular ROS was evaluated by flow cytometry and fluorescent microscopy. Briefly, the cells ( $\sim 80 \%$ confluence) were washed with PBS buffer for two times at room temperature and then were pre-treated at $37^{\circ} \mathrm{C}$ with or without olmesartan (AT1R blocker), PD123319 (AT2R blocker), NAC (scavenger of free radicals) or PDTC (NF- $\mathrm{kB}$ inhibitor) for $30 \mathrm{~min}$, and then exposed to Ang II $\left(10^{-6} \mathrm{M}\right)$ for $12 \mathrm{~h}$ in $10 \%$ FBS medium (Gibco; Thermo Fisher Scientific, Inc.). The cells were washed with fetal calf serum-free medium for two times at room temperature and cultured in a-MEM containing $10 \mu \mathrm{M}$ DCFH-DA (s0033, Beyotime Institute of Biotechnology, Jiangsu, China) for $30 \mathrm{~min}$ at $37^{\circ} \mathrm{C}$ in $5 \% \mathrm{CO}_{2}$ and $95 \%$ air. The cells were then digested with $0.25 \%$ pancreatic enzyme (Gibco; Thermo Fisher Scientific, Inc.) and were resuspended in PBS buffer. The contents of intracellular ROS which were detected by dichlorodihydrofluorescein diacetate (s0033; Beyotime Institute of Biotechnology) were analyzed by flow cytometry using
FACSort flow cytometer (BD Biosciences, Franklin Lakes, NJ, USA). In addition, the intracellular ROS were analyzed via fluorescent microscopy at an excitation wavelength of $488 \mathrm{~nm}$ prior to digestion with $0.25 \%$ pancreatic enzyme.

Statistical analysis. All data are presented as the mean \pm standard deviation. Multiple comparisons were assessed by analysis of variance followed by post hoc least significant difference test using SPSS version 17.0 (SPSS, Inc., Chicago, IL, USA). $\mathrm{P}<0.05$ was considered to indicate a statistically significant difference.

\section{Results}

Ang II induces MCP-1 expression in osteoblasts. To determine the effect of Ang II on MCP-1 expression in osteoblasts, MC3T3-E1 cells were treated with or without various concentrations of Ang II $\left(10^{-9}-10^{-5} \mathrm{M}\right)$ for $24 \mathrm{~h}$. The results showed that treatment with $10^{-9}-10^{-6} \mathrm{M}$ Ang II increased the levels of MCP-1 in MC3T3-E1 cells in a dose-dependent manner, but treatment with $10^{-5} \mathrm{M}$ Ang II slightly reduced the levels of MCP-1, relative to that of $10^{-6} \mathrm{M}$ Ang II (Fig. 1A). Furthermore, treatment with $10^{-6} \mathrm{M}$ Ang II enhanced MCP-1 expression in 
A

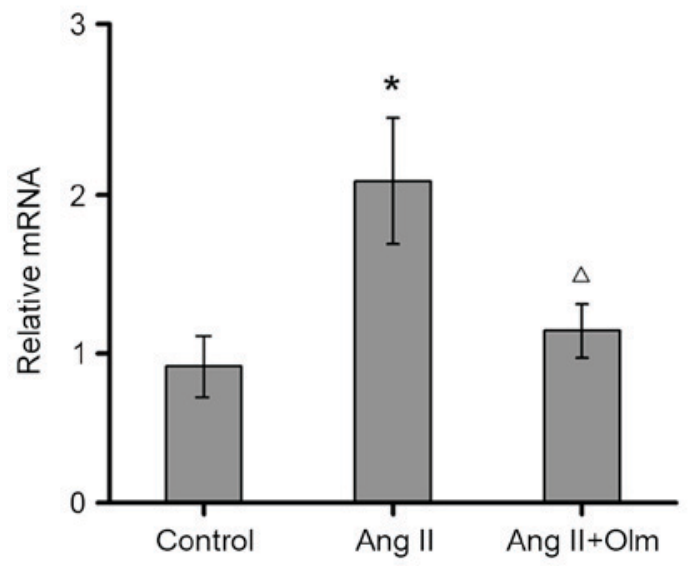

B
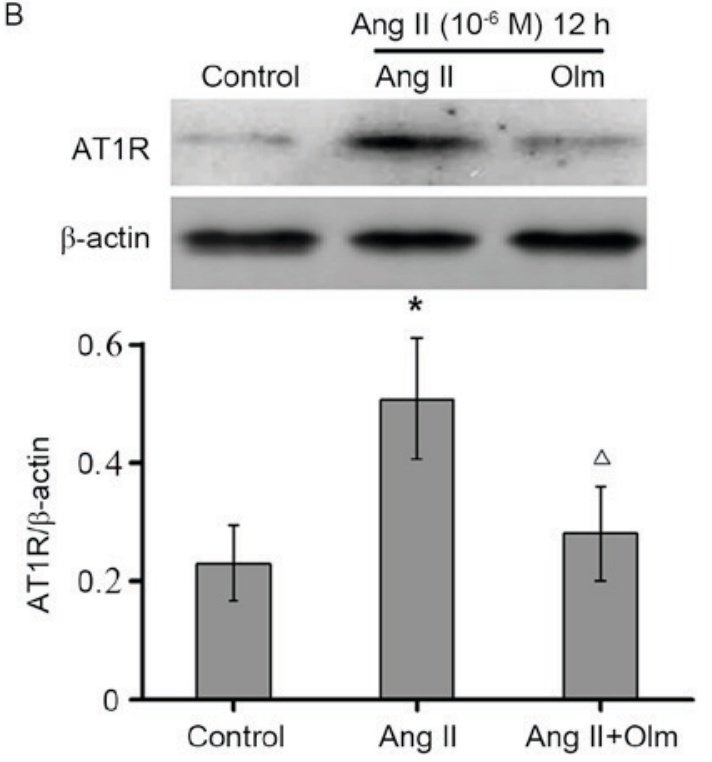

C
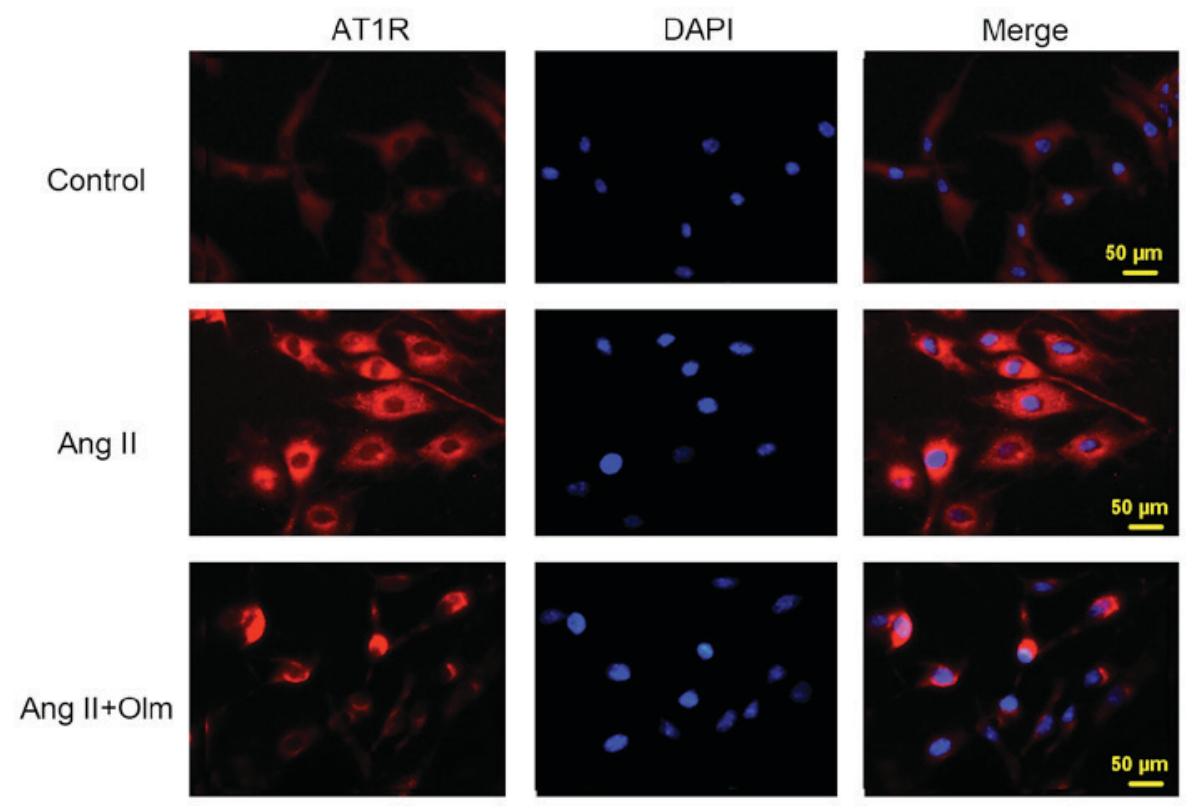

Figure 2. Effects of Ang II on AT1R expression in osteoblasts. Osteoblasts were pre-treated with olmesartan $\left(10^{-5} \mathrm{M}\right)$ for 30 min and exposed to Ang II $\left(10^{-6} \mathrm{M}\right)$ for $12 \mathrm{~h}$. (A) mRNA and (B) protein expression levels of AT1R, as determined by reverse-transcription-quantitative polymerase chain reaction and western blot analysis, respectively. Data are presented as the mean \pm standard deviation. ${ }^{*} \mathrm{P}<0.05$ vs. control; ${ }^{\wedge} \mathrm{P}<0.05$ vs. Ang II. (C) Immunofluorescence images of AT1R. Ang II, angiotensin II; AT1R, angiotensin II type 1 receptor; Olm, olmesartan.

MC3T3-E1 cells in a time-dependent manner (Fig. 1B). The enhanced effect of Ang II on MCP-1 mRNA (Fig. 1C) and serum (Fig. 1D) expression levels was completely abrogated by pre-treatment with olmesartan (an AT1R blocker), NAC (a scavenger of free radicals) or PDTC (a NF- $\kappa \mathrm{B}$ inhibitor), but not by PD123319 (an AT2R antagonist). Therefore, AT1R-associated ROS production and associated NF- $\mathrm{NB}$ signaling pathways may be important for Ang II-induced MCP-1 expression in osteoblasts.

Ang II enhances AT1R expression in osteoblasts. To determine whether Ang II induces AT1R expression in osteoblasts, the levels of AT1R expression were measured by RT-qPCR and western blot assays. Treatment with Ang II upregulated AT1R mRNA (Fig. 2A) and protein (Fig. 2B) expression levels in osteoblasts, which was completely blocked by the selective AT1R antagonist of olmesartan. A similar pattern of AT1R expression was detected by immunofluorescent assay (Fig. 2C). Thus, Ang II upregulates AT1R expression in osteoblasts in vitro.

Ang II induces ROS production via ATIR in osteoblasts. To examine the effects of Ang II on ROS production in osteoblasts, MC3T3-E1 cells were pre-treated with or without olmesartan, PD123319, NAC or PDTC, and then exposed to Ang II $\left(10^{-6} \mathrm{M}\right)$ for $12 \mathrm{~h}$. The contents of intracellular ROS were determined by flow cytometry (Fig. 3A and B) and immunofluorescent assays (Fig. 3C). The results indicated that treatment with Ang II significantly increased the levels of intracellular ROS in osteoblasts, which was abrogated by pre-treatment with olmesartan or NAC, but not PD123319 or PDTC (Fig. 3). These data suggested that Ang II increased 
A
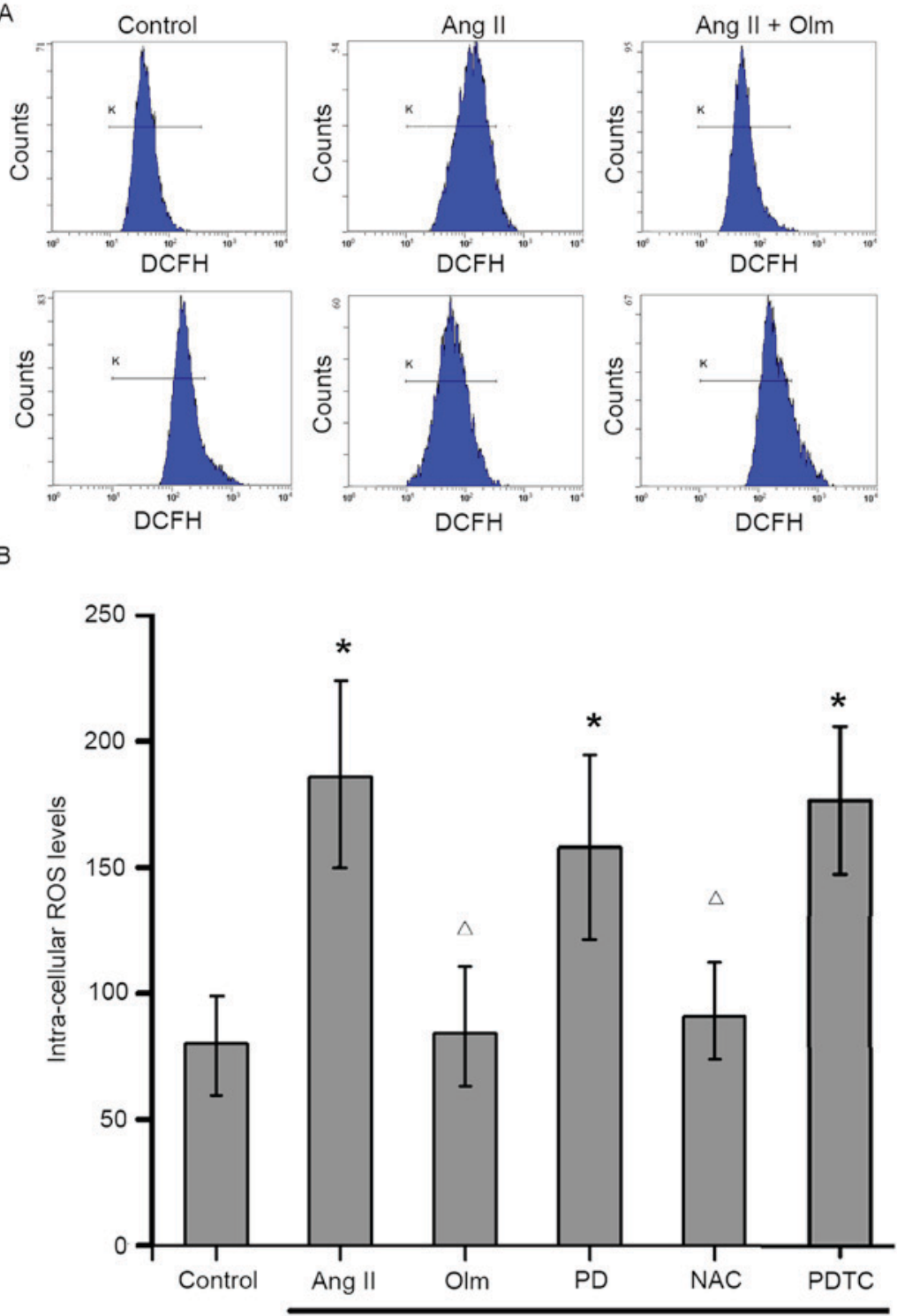

Ang $\|\left(10^{-6} \mathrm{M}\right) 12 \mathrm{~h}$

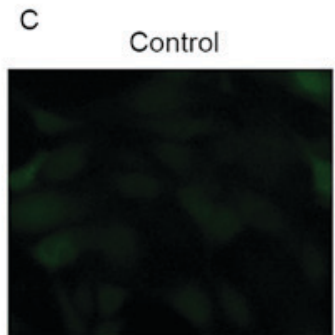

Ang II +PD

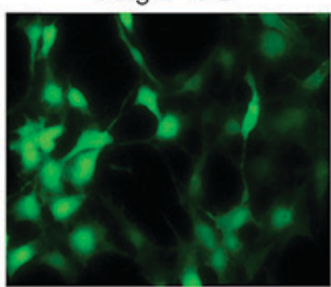

Ang II

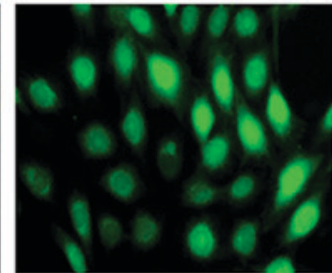

Ang $\|+N A C$

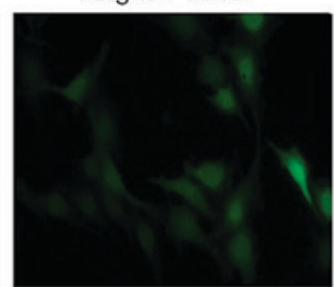

Ang $\mathrm{II}+\mathrm{Olm}$

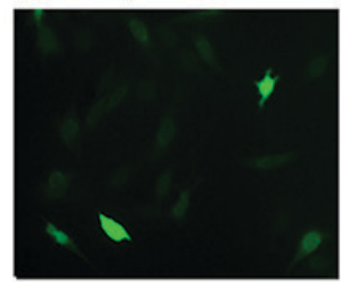

Ang II + PDTC

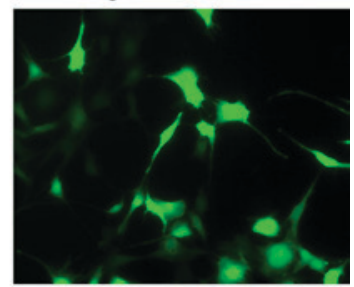

Figure 3. AngII induces ROS production in osteoblasts. Osteoblasts were pre-treated with Olm (10 $\mu \mathrm{M})$, PD (10 $\mu \mathrm{M})$, NAC (1 mM) or PDTC (5 $\mu \mathrm{M})$ for 30 min and exposed to Ang II $\left(10^{-6} \mathrm{M}\right)$ for $12 \mathrm{~h}$. The levels of intracellular ROS were determined by flow cytometry and fluorescent microscopy. (A) Flow cytometry analysis of intracellular ROS. (B) Quantitative analysis of the levels of intracellular ROS. Data are presented as the mean \pm standard deviation. ${ }^{*} \mathrm{P}<0.05$ vs. control; ${ }^{\wedge} \mathrm{P}<0.05$ vs. Ang II. (C) Fluorescent microscopy analysis. Olm, olmesartan; PD, PD123319; NAC, N-acetylcysteine; PDTC, ammonium pyrrolidine thiocarbamate; ROS, reactive oxygen species; Ang II, angiotensin II. 
A
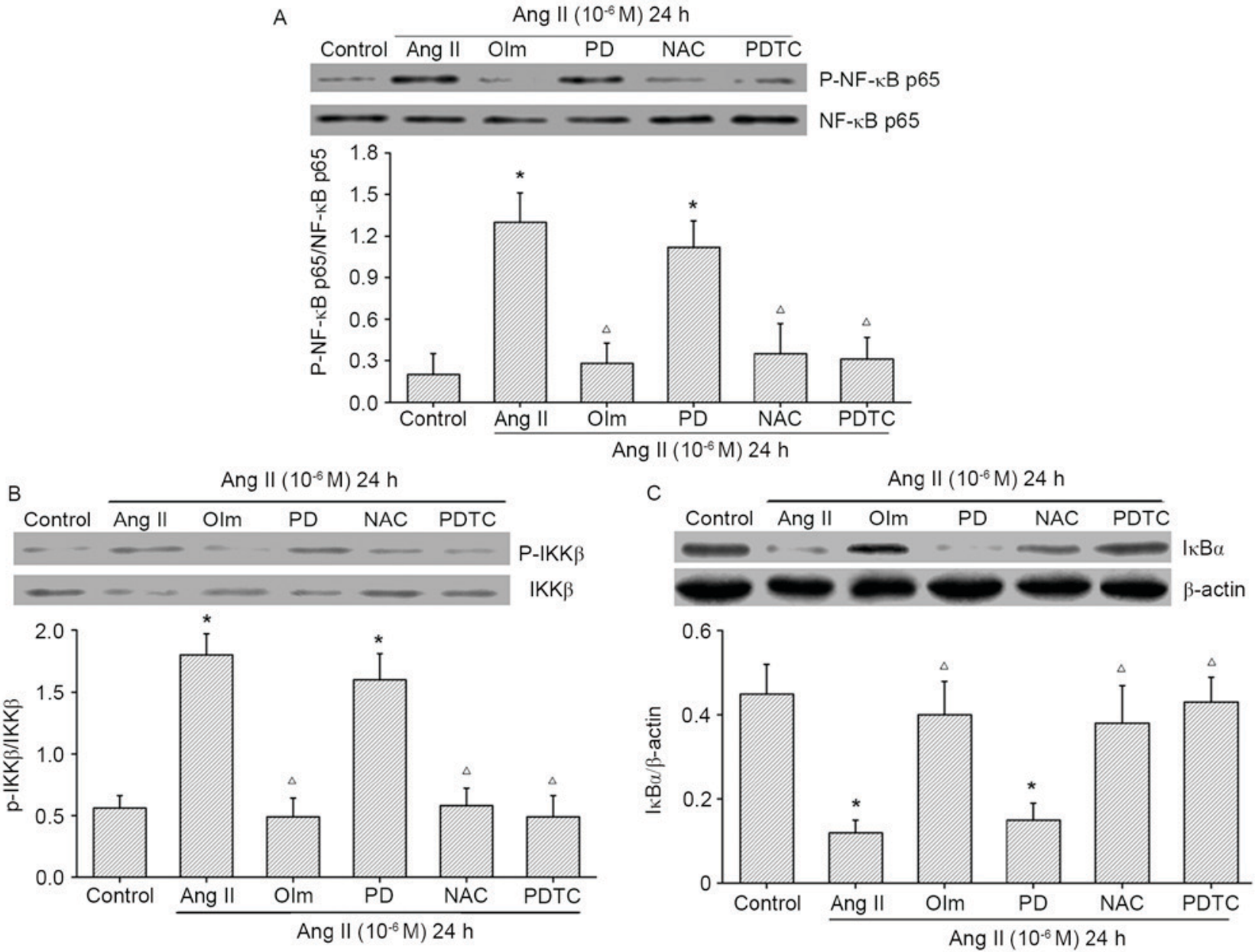

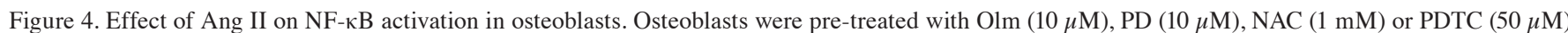
for $30 \mathrm{~min}$, and exposed to Ang II $\left(10^{-6} \mathrm{M}\right)$ for $24 \mathrm{~h}$. Representative western blot images and quantification of (A) NF- $\kappa \mathrm{Bp} 65$ phosphorylation, (B) IKK $\beta$

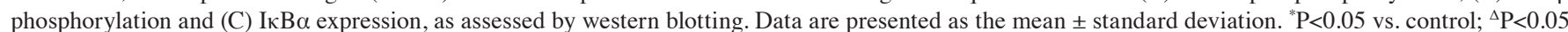
vs. Ang II. Olm, olmesartan; PD, PD123319; NAC, N-acetylcysteine; PDTC, ammonium pyrrolidine thiocarbamate; Ang II, angiotensin II; p, phosphorylated; IKK, IкB kinase; NF, nuclear factor.

ROS production by activating AT1R, but is independent of $\mathrm{NF}-\kappa \mathrm{B}$ signaling in osteoblasts.

Ang II induces $N F-\kappa B$ activation in osteoblasts. As NF- $\kappa \mathrm{B}$ activation is important for Ang II to enhance MCP-1 expression, the levels of the NF- $\kappa \mathrm{B}$ activation in the different groups of cells were examined by western blot assays. Treatment with Ang II significantly increased NF- $\kappa$ B p65 and IKK $\beta$ phosphorylation (Fig. 4A and B, respectively), but decreased the levels of I $\mathrm{B} \alpha$ protein expression (Fig. 4C) in MC3T3-E1 cells. However, the enhanced effect of Ang II on the NF- $\mathrm{B}$ activation was completely abrogated by pre-treatment with olmesartan, NAC, or PDTC, but not with PD123319 in osteoblasts (Fig. 4). Therefore, Ang II may promote ROS production via its AT1R, and subsequently activate the NF- $\kappa$ B signaling pathway, leading to enhanced MCP-1 expression in osteoblasts.

\section{Discussion}

The present study examined the effect of Ang II on MCP-1 expression and potential mechanisms underlying the action of Ang II in osteoblasts. These data indicated that treatment with Ang II significantly upregulated MCP-1 synthesis in osteoblasts, which was abrogated by pre-treatment with the AT1R inhibitor olmesartan, scavenger of free radicals (NAC), and the NF- $\kappa$ B inhibitor PDTC, but not the AT2R antagonist PD123319. These data demonstrated that Ang II enhances MCP-1 generation in MC3T3-E1 cells via its AT1R, dependent on $\mathrm{ROS} / \mathrm{NF}-\kappa \mathrm{B}$ signaling.

Ang II is a potent stimulator of osteoclastic bone resorption (12,13). Although Ang II does not target osteoclasts (4), it may stimulate RANK and interleukin-6 expression in osteoblasts, which promotes osteoclast maturation, leading to osteoporosis $(3,4,14)$. The present study demonstrated that Ang II enhances MCP-1 expression in osteoblasts, which previous studies have revealed should promote osteoclast maturation and activation $(15,16)$. Therefore, these findings may provide novel insight into regulation of Ang II on bone metabolism and homeostasis.

Ang II can bind to ATIR and AT2R, which are expressed by osteoblasts $(17,18)$. The present study demonstrated that the enhanced effect of Ang II on MCP-1 expression was completely mitigated by pre-treatment with the AT1R antagonist olmesartan, but not with the AT2R antagonist PD123319, indicating that Ang II enhances MCP-1 expression in osteoblasts via AT1R, but not AT2R. These data were 
consistent with a previous study (17), supporting the notion that Ang II induces MCP-1 expression, dependent on the AT1R (7). Furthermore, treatment with Ang II was revealed to upregulate AT1R expression in osteoblasts, consistent with previous findings $(5,19)$. Upregulated AT1R may serve as a positive feedback mechanism to enhance the effect of Ang II on MCP-1 expression and other bioactivities in osteoblasts.

Ang II may induce ROS production in vascular smooth muscle cells (20). To understand the molecular mechanisms underlying the action of Ang II, the present study investigated the effect of Ang II on ROS production in osteoblasts. Treatment with Ang II stimulated ROS production in osteoblasts, which was abrogated by pre-treatment with an AT1R antagonist and the ROS scavenger NCA. These data suggested that Ang II stimulated ROS production in osteoblasts via AT1R, which was similar to the results of our previous experiment (5). As high levels of ROS can activate NF- $\kappa B$ signaling (21) and pre-treatment with PDTC mitigates Ang II-induced MCP-1 expression in osteoblasts, the present study examined the effect of Ang II on NF- $\kappa B$ activation in osteoblasts. It was demonstrated that treatment with Ang II enhanced NF- $\kappa B$ activation, evidenced by increased ratios of NF- $\mathrm{kBp} 65$ and IKK $\beta$ phosphorylation and decreased levels of IкB $\alpha$ expression in osteoblasts. The enhanced effect of Ang II on the $\mathrm{NF}-\kappa \mathrm{B}$ activation was completely blocked by pre-treatment with an AT1R antagonist, an NF- $\mathrm{BB}$ inhibitor and the ROS scavenger NCA in osteoblasts. These novel data indicated that Ang II stimulated ROS production via its AT1R, which activated NF- $\kappa \mathrm{B}$ signaling, leading to upregulated MCP-1 expression in osteoblasts. MCP-1 is important for regulating osteoclast maturation activation, and the increased levels of MCP-1 expression by osteoblasts may promote osteoclast activation and osteoporosis. Therefore, the Ang II/AT1R/MCP-1 axis may be a novel target for intervention of osteoporosis.

In conclusion, these data indicated that Ang II stimulated ROS production via ATIR, and activated the NF- $\mathrm{KB}$ signaling pathway, leading to upregulated MCP-1 expression in osteoblasts. These findings may provide novel insights into understanding the action of Ang II in regulating bone metabolism and homeostasis, and may facilitate the development of novel therapies for osteoporosis.

\section{Acknowledgements}

The present study was supported by the National Natural Science Foundation of China (grant nos. 81601875, 81472067 and 81772329) and the Shandong Provincial Natural Science Foundation, China (grant no. ZR2016HB33).

\section{References}

1. Leung PS: The peptide hormone angiotensin II: Its new functions in tissues and organs. Curr Protein Pept Sci 5: 267-273, 2004.

2. Simões E, Silva AC and Teixeira MM: ACE inhibition, ACE2 and angiotensin-(1-7) axis in kidney and cardiac inflammation and fibrosis. Pharmacol Res 107: 154-162, 2016.

3. Asaba Y, Ito M, Fumoto T, Watanabe K, Fukuhara R, Takeshita S, Nimura Y, Ishida J, Fukamizu A and Ikeda K: Activation of renin-angiotensin system induces osteoporosis independently of hypertension. J Bone Miner Res 24: 241-250, 2009.
4. Shimizu H, Nakagami H, Osako MK, Hanayama R, Kunugiza Y, Kizawa T, Tomita T, Yoshikawa H, Ogihara T and Morishita R: Angiotensin II accelerates osteoporosis by activating osteoclasts. FASEB J 22: 2465-2475, 2008.

5. Zhang Y, Zhang Y, Kou J, Wang C and Wang K: Role of reactive oxygen species in angiotensin II: Induced receptor activator of nuclear factor- $\mathrm{\kappa B}$ ligand expression in mouse osteoblastic cells. Mol Cell Biochem 396: 249-255, 2014.

6. Ohba T, Cole HA, Cates JM, Slosky DA, Haro H, Ando T, Schwartz HS and Schoenecker JG: Bisphosphonates inhibit osteosarcoma-mediated osteolysis via attenuation of tumor expression of MCP-1 and RANKL. J Bone Miner Res 29: $1431-1445,2014$

7. Pan Q, Yang XH and Cheng YX: Angiotensin II stimulates MCP-1 production in rat glomerular endothelial cells via $\mathrm{NAD}(\mathrm{P}) \mathrm{H}$ oxidase-dependent nuclear factor-kappa B signaling. Braz J Med Biol Res 42: 531-536, 2009.

8. Tanifuji C, Suzuki Y, Geot WM, Horikoshi S, Sugaya T, Ruiz-Ortega M, Egido J and Tomino Y: Reactive oxygen species-mediated signaling pathways in angiotensin II-induced MCP-1 expression of proximal tubular cells. Antioxid Redox Signal 7: 1261-1268, 2005.

9. Zhao J, Liu J, Pang X, Wang S, Wu D, Zhang X and Feng L: Angiotensin II induces $\mathrm{C}$-reactive protein expression via AT1-ROS-MAPK-NF- $\kappa$ B signal pathway in hepatocytes. Cell Physiol Biochem 32: 569-580, 2013.

10. Wang JC, Zhao Y, Chen SJ, Long J, Jia QQ, Zhai JD, Zhang Q, Chen Y and Long HB: AOPPs induce MCP-1 expression by increasing ROS-mediated activation of the NF- $\kappa \mathrm{B}$ pathway in rat mesangial cells: Inhibition by sesquiterpene lactones. Cell Physiol Biochem 32: 1867-1877, 2013.

11. Livak KJ and Schmittgen TD: Analysis of relative gene expression data using real-time quantitative PCR and the 2(-Delta Delta C(T)) method. Methods 25: 402-408, 2001.

12. Hatton R, Stimpel M and Chambers TJ: Angiotensin II is generated from angiotensin I by bone cells and stimulates osteoclastic bone resorption in vitro. J Endocrinol 152: 5-10, 1997.

13. Chen S, Grover M, Sibai T, Black J, Rianon N, Rajagopal A, Munivez E, Bertin T, Dawson B, Chen Y, et al: Losartan increases bone mass and accelerates chondrocyte hypertrophy in developing skeleton. Mol Genet Metab 115: 53-60, 2015.

14. Guo L, Wang M, Zhang ZY, Hao L, Lou BY, Li XY, Loo WT, Jin L and Cheung MN: Angiotensin II induces interleukin-6 synthesis in osteoblasts through ERK1/2 pathway via AT1 receptor. Arch Oral Biol 56: 205-211, 2011.

15. Li X, Qin L, Bergenstock M, Bevelock LM, Novack DV and Partridge NC: Parathyroid hormone stimulates osteoblastic expression of MCP-1 to recruit and increase the fusion of pre/osteoclasts. J Biol Chem 282: 33098-33106, 2007.

16. Miyamoto K, Ninomiya K, Sonoda KH, Miyauchi Y, Hoshi H, Iwasaki R, Miyamoto $\mathrm{H}$, Yoshida S, Sato Y, Morioka H, et al: MCP-1 expressed by osteoclasts stimulates osteoclastogenesis in an autocrine/paracrine manner. Biochem Biophys Res Commun 383: 373-377, 2009.

17. Izu Y, Mizoguchi F, Kawamata A, Hayata T, Nakamoto $T$, Nakashima K, Inagami T, Ezura Y and Noda M: Angiotensin II type 2 receptor blockade increases bone mass. J Biol Chem 284: 4857-4864, 2009.

18. Nakai K, Kawato T, Morita T, Iinuma T, Kamio N, Zhao N and Maeno M: Angiotensin II induces the production of MMP-3 and MMP-13 through the MAPK signaling pathways via the AT(1) receptor in osteoblasts. Biochimie 95: 922-933, 2013.

19. Liu JJ, Li DL, Zhou J, Sun L, Zhao M, Kong SS, Wang YH, Yu XJ, Zhou J and Zang WJ: Acetylcholine prevents angiotensin II-induced oxidative stress and apoptosis in H9c2 cells. Apoptosis 16: 94-103, 2011.

20. Bruder-Nascimento T, Chinnasamy P, Riascos-Bernal DF, Cau SB, Callera GE, Touyz RM, Tostes RC and Sibinga NE: Angiotensin II induces Fat1 expression/activation and vascular smooth muscle cell migration via Nox1-dependent reactive oxygen species generation. J Mol Cell Cardiol 66: 18-26, 2014.

21. Yang X, Wang Y and Gao G: High glucose induces rat mesangial cells proliferation and MCP-1 expression via ROS-mediated activation of NF- $\kappa \mathrm{B}$ pathway, which is inhibited by eleutheroside E. J Recept Signal Transduct Res 36: 152-157, 2016. 